\title{
CORRELATION BETWEEN THE PARTICIPATION OF ELDERLY PEOPLE IN THE OCCUPATIONAL THERAPY AND THEIR ASSESSMENT OF THE HEALTH-RELATED QUALITY OF LIFE
}

\author{
Hanna Nałęcz, Jolanta Derbich
}

\author{
Józef Piłsudski University of Physical Education in Warsaw
}

Nałęcz H., Derbich J. (2014), Correlation between the participation of elderly people in the occupational therapy and their assessment of the healthrelated quality of life. Health Problems of Civilization, 4 (8), p. 54-60

\begin{abstract}
Summary: The aim of the research: discovering the relation between the participation of elderly people in the occupational therapy and their Health-Related Quality of Life. Research material and methods: research was carried out in the public social centres offering the occupational therapy devoted to the elderly people. 95 people whose average age was 72,1 years (58 women and $37 \mathrm{men}$ ) were examined. The examinees were divided into two groups: the participants and those who were not involved in the occupational therapy. The method of direct interview using EQ-5D-3L questionnaire - a standard instrument for measuring Health-Related Quality of Life of the elderly people was applied.

The results: Seniors involved in occupational therapy reported better HRQL. Difficulties with mobility $(<0,05)$, pain/discomfort $(<0,001)$ and anxiety $(<0,001)$ were substantially more visible around people who did not take part in the occupational therapy. The average self-reported health was better among the occupational therapy participants $(<0,001)$ in comparison with the other elderly people who were not engaged in those activities (76,5 vs. 43,6 respectively).

Conclusions: participation in the occupational therapy has a positive effect on the functioning of the elderly people in every sphere of their life: physical, mental and social one. Involvement in the occupations resulted in the improved perception of the Health-Related Quality of Life. Occupational therapy turned out to be an inexpensive and effective method that exerts a positive impact on maintenance of physical and intellectual abilities, social inclusion as well as physical rehabilitation of seniors.
\end{abstract}

Keywords: occupational therapy, seniors, quality of life, self-evaluation of health status, EQ5D, VAS

\section{Introduction}

In the European Union states, the age of 65 is acknowledged as delimitation of the old age boundary (http:// www.euro.who.int). Seniors constitute a population that is in the spotlight of the scientist dealing with distinct areas of research. The reason of this intensified attention set on the groups of the elderly is the fact that due to dynamic demographic changes, the lifespan increases along with the growing number of people with decreasing functional capacity. Alongside, the need for prevention of the involutionary processes raises.

The process of ageing affects every structure and function of the organism. It is related to co-occurrence of many alternations and disorders, the increased risk of many diseases and the simultaneous treatment of those. Hence, the elderly people are among the most numerous groups that make use of the physiotherapy and occupational therapy as well (Steultjens et al. 2004). Engaging in either individual or organized forms of therapy and entertainment allows people of old age to maintain independence, self-reliance and use their lives optimally to the full. It also bears a great deal of significance for the perception of one's health and quality of life.

According to a definition coined by the World Health Organization, the quality of life is related to, as a subjective perception of one's life status interpreted through the context of a given culture, system of values and in relation to personal goals, expectations, standards and interests of an individual. The wide spectrum which this expression encompasses allows to embrace the essence of person's physical health, state of mind, level of independence, social relations, personal believes and relation to the most relevant characteristics of one's environment (The WHOQOL Group 1994).

Address for correspondence: Hanna Nałęcz, Józef Piłsudski University of Physical Education in Warsaw, 34 Marymoncka Street, 00-986 Warsaw, e-mail: hanna.nalecz@awf.edu.pl,phone: 22 834-04-31 w. 336

Tables: 1 Figures: 3 References: 21 Full-text PDF www.hpc.edu.pl Copyright (C) Pope John Paul II State School of Higher Education in Biała Podlaska, Sidorska 95/97, 21-500 Biała Podlaska Indexation: Index Copernicus, Database AGRO, ProQuest, Polish Ministry of Science and Higher Education. This is an open-access article distributed under the terms of the Creative Common Attribution Non-commercial license (http://creativecommons.org/ licenses/by-nc/3.0), which permits use, distribution and reproduction in any medium, provided the original works is properly cited, the use is noncommercial and is otherwise in compliance with the license. 
An interest in the matters related to the Quality of Life (QoL) is connected with the imprinted in the memory of scientists researching holistic definition of health, which has been operating in the spectrum of medicine and public health since 1948 (Nutbeam 1998). In the light of such perspective on medicine, in the process of its maintenance and recuperation, the physiological parameters cannot be those solely taken into consideration. Notion of the QoL, which can as well be multi-dimensional describes those matters that are most valid for the individual person in assessing his/her health status.

Medicine takes an interest in the Quality of Life mainly in relation to the analysis of the end points, which in clinical examination are among other results of the laboratory tests, the range of everyday patients' activities and self-evaluation of well-being, thus in general indices of the Quality of Life. The scientists make use of the HealthRelated Quality of Life (HRQL) (Jaeschke 1999).

In the environment of seniors, the correlation between health and Quality of Life marks itself as specially significant. Efficient and self-reliable functioning in everyday life, which gives oneself the feeling of stability and independence is connected with the constant care for maintenance of health and efficiency of psychomotoric functions. The occupational therapy brings excellent results within this area. Since 1990s, according to principles of Evidence Based Medicine (EBM), the articles that acknowledge the thesis about the effect occupational therapy has on its participants' health improvement and slowing down the ageing processes, especially in the context of large communities, in which the elderly live and function everyday has been published. (Clark et al. 1997, Alpert et al. 2009).

The occupational therapy consists in many activities focused on support, health and well-being recuperation through occupations. Everyday activities such as: play, work, self- service activities, chores at home, recreation or hobby can be a way to health and well-being maintenance and simultaneously serve as a therapeutic instrument (Perrin 2005). Aim of the occupational therapy always depends on the individual needs and capabilities, but generally it can be specified as a help in pursuing of maximal level of independence, increase of self-confidence and feeling of self-worth (McCormac 1997).

Taking into account the sphere of needs, the elderly are a specific group that makes use of the therapy. Multimorbidity, impairment of the organs of the sensory system, debilitation of the cognitive processes, psychogeriatric syndroms, lack of motivation, mood swings, lesser potential for rehabilitation and the apprehension to come to normal activities, decreased functional ability (control and coordination disorders), as well as a general inclination for tiredness and hypokinesia with its somatic and social outcomes (Kostka P., Kostka J., 2011).

Taking into account as general medical approach concerned on the end points analysis during treating senior patients and psycho-social perspective (the concept of prosperous ageing process and support for the qualifications of the elderly people) homogeneity of ideas and endeavors is noticeable in both approaches (Fernandez-Ballesteros 2006).

It is worth to notice the fact that the concept of Health-Related Quality of Life (HRQL) connects both directions of thoughts and actions into one consistent approach. Theoretical bases and examinations providing us with a positive result of a correlation between the occupational therapy and Health-Related Quality of Life can be found as early as in the works of Jackson and other scientists from 1998. Those dissertations describe the positive relation between the client centered practice in the occupational therapy and effect it exerts on the health and well-being recuperation of the elderly people(Jackson et al. 1998).

The goal of the examinations was to point out the correlation between the Health-Related Quality of Life of the elderly people and their participation in the occupational therapy. The examination was carried out on the sample of seniors living in Warsaw.

\section{Study material and methods}

The study was conducted in 2011 as a part of the scholarship project "Development of the pedagogic- scientific potential within the scope of the occupational therapy as a key to Higher Education development" co-financed by the European Social Fund. The project was executed in 2010-2012 at the University of Physical Education in Kraków, University of Physical Education in Warsaw and University of Physical Education in Wrocław and The School of Administration in Bielsko Biała. The schedule of the research as well as the bioethical sphere of the project was approved by the Scholarship Project Committee.

The research was carried out in Warsaw and the central institutions that constituted a form of operator selecting the seniors from the Senior Clubs in each town district were designated by the relevant district offices. Examinees were selected (purpose selection) and divided into two groups: participation (at least for 6 months) or lack of participation (at least for 6 months) in the occupational therapy at the social centre.

The therapy in the selected centers was carried out as an art therapy, which was mainly focused on the manual skills. Its aim was to share interests and passions of the participants, improve the communicative skills and 
interpersonal relations - as elements of social rehabilitation, boost and maintain the simple coordinative-motor functions (fine motor skills). 95 people were examined, whose average age was 72,1 $\pm 4,4$ years. Survey method and interview technique were used, along with the EQ-5D-3L questionnaire, in Polish. EQ-5D-3L is a standardized tool formulated by EuroQuol Group and it is used to assess health and Health-Related Quality of Life. A written approval for usage of the questionnaire was attained from a full copyright owner (EuroQol Group 1990). This tool consists of two parts. In the first part (EQ-5D), the examinee describes his or her wellbeing in 5 dimensions: mobility, self-service activities, everyday chores, feeling of pain/discomfort, anxiety/depression. The assessment is carried out by marking the answers with values from 1 to 3 , for which 1 means lack of problems and 3 stands for the intensified problems. The Visual Analogue Scale (VAS) constitutes the second part of the questionnaire, which operates on the scale of $0-100$. Respondents are assessing their health at the moment of filling the questionnaire by allocating a particular scale value.

The research paper analyzed the Health-Related Quality of Life expressed by the two dependent variables: selfreported health and the occurrence of problems (five dimensions - five constituent variables: mobility, self-care, usual activities, feeling of pain/discomfort and anxiety/depression; and independent variables: the participation in the occupational therapy, gender and age of the patients.

In the statistical analyses the cross-tabulation with chi-square test, analysis of variance ANOVA, the multilevel logistic regression modeling and the generalized linear model (GLM) were used.

\section{Results}

58 women (SD 70,57 $\pm 3,88$ years old) and 37 men (SD 74,57 \pm 4,02 years old) were examined. 47 person, 21 of which were men and 26 women, from the whole group took part in the occupational therapy. The age structure is presented in the table 1 . The most numerous age category in the examined group was ranging between 70 and 75 years, both women and men. The youngest examined person was 66 years old, whereas the oldest was 84 .

Table 1. Age and gender structure of examinees

\begin{tabular}{|l|c|c|c|c|c|}
\hline \multicolumn{1}{r|}{ Gender } & Total & 66-69 years old & 70-75 years old & 76-79 years old & 80 years old and more \\
\hline Women & 58 & 21 & 31 & 4 & 2 \\
\hline Men & 37 & 4 & 18 & 11 & 4 \\
\hline Total & 95 & 25 & 49 & 15 & 6 \\
\hline
\end{tabular}

\section{The correlation of the analyzed variables with examinees' gender and age}

The cross tabulation with chi-square test, analysis of variance ANOVA were used to assess the relation of the variables with examinees' gender and age. Gender did not significantly diversify people's participation in the therapy. The age structure was more substantial for the involvement in the therapy $(\mathrm{p}<0,05)$. Younger people made use of the therapy more often than the older ones. Taking into account the variables of gender and age and analyzing its effect on the frequency of the therapy attendance, the results showed that younger women were engaged in the therapy more often $(\mathrm{p}<0,001)$.

The occurrence of anxiety and depression was correlated with patients' gender- women enumerated this ailment more often than men $(\mathrm{p}<0,05)$. Feeling of pain/discomfort was related to age - people that passed the age of 69 felt the pain or experienced discomfort more often than their younger friends $-(\mathrm{p}<0,05)$.

The analysis of variance ANOVA has shown that the self-reported health was not dependent on gender or age.

\section{The correlation of Health-Related Quality of Life with the participation in the occupational therapy}

The cross tabulation with chi-square test demonstrated the existence of statistically significant differences between the problems occurrence in 3 from 5 analyzed dimensions and the seniors' participation in the occupational therapy. The elderly people that were not attending the therapy substantially more often complained about the ailments connected with: mobility $(\mathrm{p}<0,05)$; feeling of pain/discomfort $(\mathrm{p}<0,001)$; anxiety/depression $(\mathrm{p}<0,001)$ (Figure 1). 


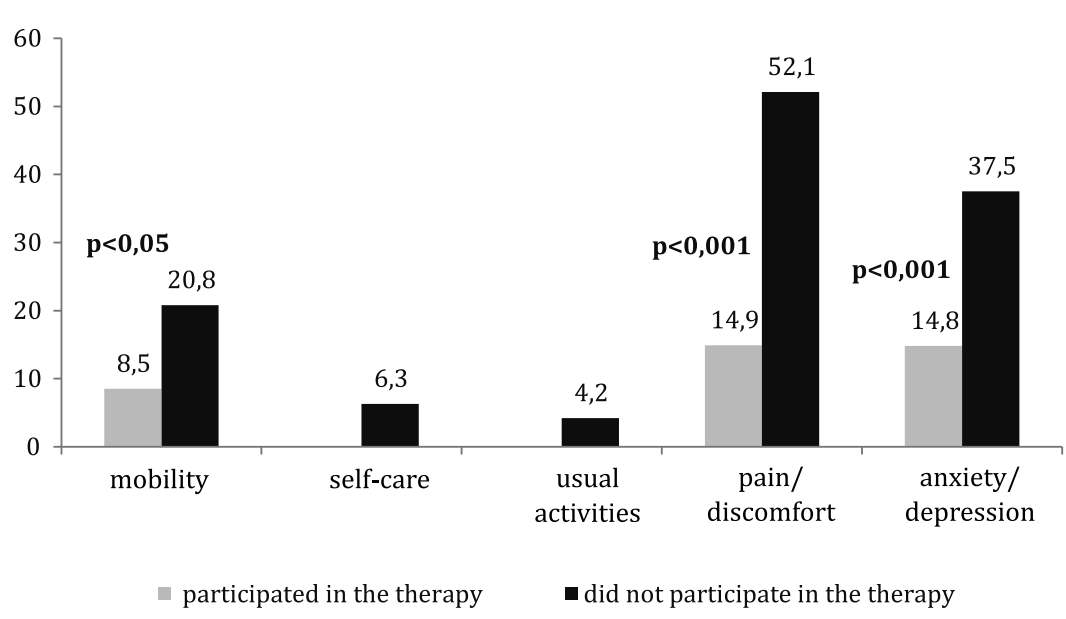

Figure 1. The correlation between the problems seniors complained about and their participation in the occupational therapy (\% of examinees)

Within the analysis of variance ANOVA, the average self-evaluation of health that was measured on VAS scale was compared with the resulting correlation with the examinees' participation in the occupational therapy. Persons that partook in the therapy assessed their health on the higher level $(p<0,001)$. The average VAS scale value amounted to 76,53 with $95 \%$ confidence intervals. $[72,96-80,10]$. People who did not join the classes attained a total average self-evaluation of their health that equals 43,60; PU [39,51-47,7].

\section{The correlation of Health-Related Quality of Life with the attendance at the occupational therapy and age - interaction}

Applying the multidimensional logistic regression modeling the possibility of the particular ailments occurrence quotients were established. They comprise the total HRQL depending on participation of the seniors in the therapy and their gender and age. An important co-variation was noted in cases of two domains: pain/ discomfort and anxiety/depression. Being engaged in the therapy has considerably reduced the risk of problems in both dimensions ( $\mathrm{p}<0,001$ and $\mathrm{p}<0,05$ respectively). Moreover, the risk of feeling pain was augmented by the age of the patients -70 years old and more $(p<0,05)$ and the risk of experiencing anxiety or depression was smaller among men in comparison to women $(p<0,05)$. The values showing the odds ratio $(\mathrm{OR})$ and confidence intervals are presented at Figure 2.

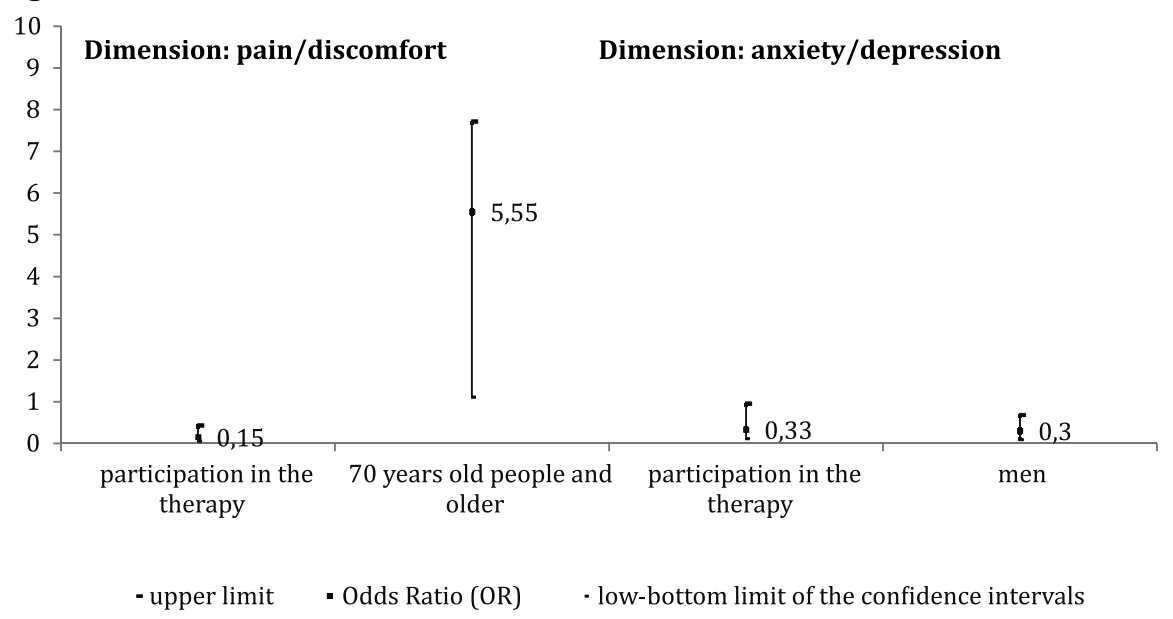

Figure 2. Factors that limit and intensify the risk of occurrence of ailments: pain/discomfort and anxiety/depression (odds ratio -OR)

Using the generalized linear model (GLM) the interaction between the self-reported elderly people's health with their partaking in the occupational therapy, age and gender. In accordance with the earlier results, only the participation in the therapy considerably influenced the self-reported health $(\mathrm{p}<0,001)$. The analysis of the co- 
variation of all the examined factors did not show a statistical significance, but the strong tendency for changes was preserved, which can be inferred from the Graph no.3. Younger participants, both women and men, assessed their health at the higher level than their older friends and those who did not partake in the occupational therapy.

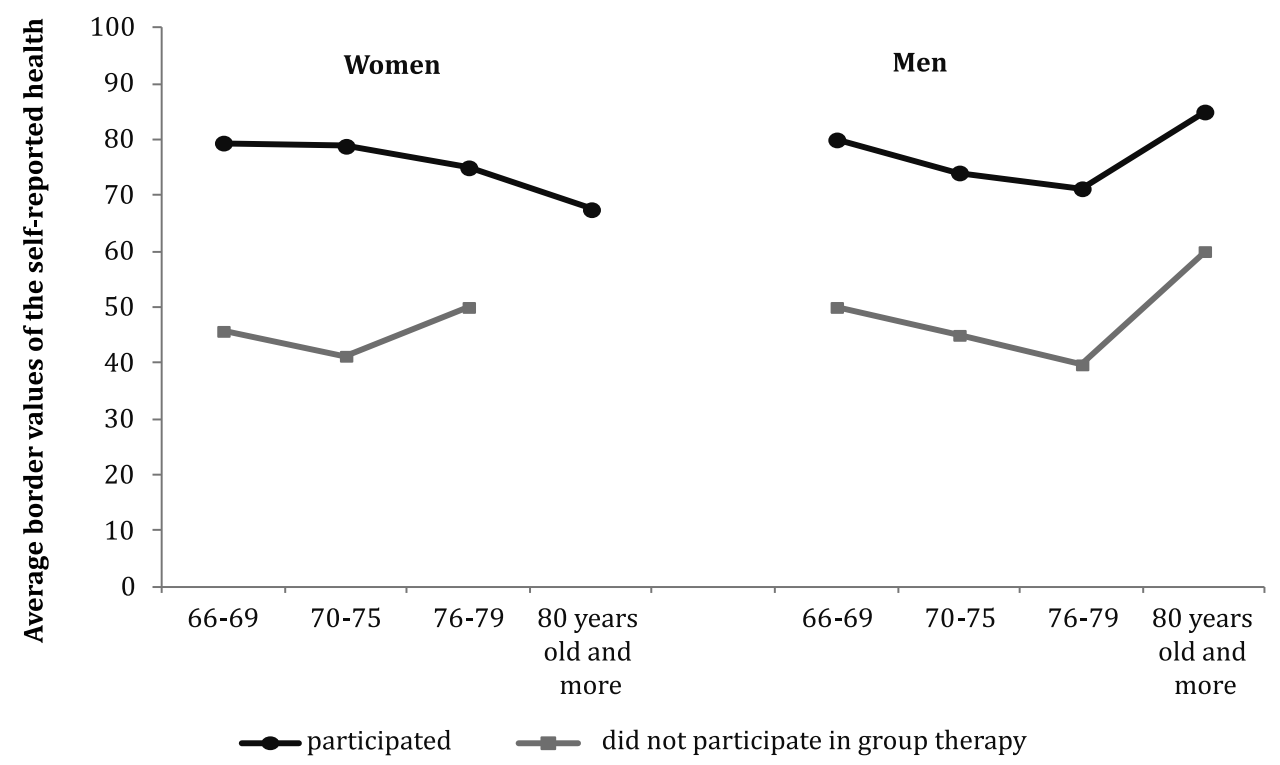

Figure 3. The relation between the participation of seniors in the occupational therapy and the problems in 5 dimensions reported by seniors (\% of the examined)

\section{Discussion}

The examinations connected with the Health-Related Quality of Life of the elderly people in the context of participation in the occupational therapy were presented in the thesis paper. While analyzing the results, two constituents of the HRQL assessment were used: an objective indicator - an intensification of the ailments occurrence within the five dimensions and a subjective indicator - the self-reported health. The inner feelings and the state of well-being of the examined people always constitute a foundation for the measure and HRQL assessment, where not only the objective indicators are taken into account. This approach relates to a "equality of rights" of the disabled or chronically sick patients, who are enabled to, along with the healthy people, assess their quality of life on the fully dimensional scale. Within the realm of the clinical examinations of a medical background HRQL is assessed on the basis of the clinical results (examination results, level of recuperation, process of curing etc...) combined with the well-being or health self-assessment. Numerous simple and complex indices of the health status diagnosis are applied e.g. Life Expectancy (LE), Quality Adjusted Life Years (QALY), Disability Adjusted Life Expectancy (DALE), Healthy Life Years (HLY) and others (Gromulska et al. 2008). Depending on the aim of the examination and needs the projects evoke, the relevant indices of the heath state are applied to specify the HealthRelated Quality of Life.

In the context of occupational therapy HRQL is used as a positive parameter of health, which is the most classic and universal definition of quality of life proposed by Thomas Gill and Alvan Frenstein. According to this approach the quality of life is a way, in which man perceives his health state as well as the reaction on it and other medical aspects of life e.g. family, work or friends (Gill and Feinstein 1994). Basing on the definition of the occupational therapy quoted earlier, the focus is placed on the client centered practice and in the therapeutic process individual needs and capabilities of a patient as well as his/her attachment to a particular social group (family, work environment, friends and acquaintances, local community) is taken into consideration.

The results of the examination conducted specify taking part in the occupational therapy as a factor contributing to a better assessment of Health-Related Quality of Life. Objective component HRQL (occurrence of problems) alike the subjective constituent (self-reported health) were represented by the higher values for patients that partook in the occupational therapy. Similar results can be found in a numerous Polish and foreign literature, in which the various therapeutic forms are proven to bear a positive impact on HRQL of the elderly people. The examinations carried out by Kathleen Matuska, which consisted in the six months participation of the elderly people in the comprehensive occupational therapy program, indicated a considerable improvement of HRQL assessment in the sphere of vitality, interaction in social groups and mental health (Matuska et al. 2003). 
Carr-Tyszka i Farber obtained interesting results. They were analyzing the effect of the healthy lifestyle campaign exerted on the involvement in the therapy and Health-Related Quality of Life and the results indicated that the promotion of the healthy lifestyle causes the significantly greater engagement in the therapy and has noticeable impact on HRQL (Carr-Tyszka i Farber 2010). The proof that there is a direct and indirect positive correlation between the occupational therapy and the patients' Health-Related Quality of Life. Program against injuries caused by falls, which was implemented in the selected group of elderly people, resulted in the improvement of the balance system and other psychophysical parameters (Krampe et al. 2010). Within the program dance classes were used as a therapy. Better assessment of quality of life was a consequence of the participation in the classes.

A similar approach, but from the other perspective, can be seen in the work of Horowitz and other scientists, who implemented a program of the occupational therapy for students, which was based on the intergenerational educational effects during the practical contacts with the elderly people in their social environment (Horowitz et al. 2010). Besides the content-related results such as an improvement of the general quality of life, an interesting program of the occupational education for therapist based on the practice was created. Metz and Robnett bring about the less popular correlation between the occupational therapy and the state of mental health. Scientists prove that the therapy has a beneficial influence on the functioning and the quality of life of the elderly people (Metz and Robnett 2011).

Concluding, Clark and other scientists, within the report from the Well Elderly 2 project, confirmed that the occupational therapy lessened the feeling of pain, improved the general organism vitality, social functioning, mental health and boosted life satisfaction of the elderly (Clark et al. 2011). HRQL was also analyzed in the context of the occupational therapy effectiveness results. In order to obtain the desired results, the QALY index was used. Its growth was noticeable in the intervention group and it corresponds to greater effectiveness.

On the basis of the examinations conducted and those mentioned earlier in the study it can be inferred that within the population of the elderly, the participation in the therapy positively affects their physical, mental health as well as social interactions, well-being and HRQL. Moreover, the character of these interrelations is extensive, consistent with the holistic concept of health and it is connected with the costs reduction for treatment and rehabilitation of the elderly.

\section{Limitations of the studies}

EQ-5D-3L questionnaire contains both - somatic and psychological element of the HRQL, but it does not diagnose the social context.

People who were qualified for the group that did not participate in the occupational therapy could be more predisposed to make worse assessments. This situation could be related to their more negative attitude towards life and towards people as well as poor social interactions - also in the sphere of the willingness to partake in the various forms of activities, including therapy.

\section{Conclusions and practical implications}

The participation of the elderly in the occupational therapy has beneficial outcomes noticeable in every aspect of their lives and functioning, within the realm of physical and mental health as well. The client centered occupational therapy additionally enables the patients to activate and join in various activities organized as a part of the community, in which they life.

Health-Related Quality of Life constitutes a positive index of health and allows to extensively diagnose the state of the patients' health, encompassing all the social groups and thus contributing to the diagnosis of the whole population's state of health.

The positive effect occupational therapy has on the Health-Related Quality of Life is broadly covered in the literature. A special attention should be spared on the aspect of holistic influence and the economic benefits that stem from the therapy organized in such a way. The fact that complex therapy can constitute a perfect foundation for the healthy lifestyle campaigns, which as indicated in the quoted theses has a direct connection with the improvement of the Health-Related Quality of Life assessment.

Engaging in the therapy can improve or help to regain the quality of life that was lost due to the process of ageing, disease or disability. It is beneficial not only to the individual patient, but also to the systemic savings. The occupational therapy should become a tool used extensively within the modern public health system that is oriented on the preventive treatment and health promotion, and not solely a short-term action. As a result, the high level of educational courses for occupational therapists becomes more and more important. 


\section{References:}

1. EuroQol Group (1990), EuroQol-a new facility for the measurement of health-related quality of life. Health Policy 16, p. 199-208.

2. Alpert P., Miller S., Wallmann H., Havey R., Cross C., Chevalia T., Gillis C., Kodandapari K. (2009), The effect of modified jazz dance on balance, cognition, and mood in older adults. Journal of the American Academy of Nurse Practitioner, 21, p. 108-115.

3. Carr-Tyszka A., Farber R. (2010), Exploring the Relation of Health-Promoting Behaviors to Role Participation and Health-Related Quality of Life in Women With Multiple Sclerosis: A Pilot Study. American Journal of Occupational Therapy 64, p. 650-659.

4. Clark F., Azen S., Zemke R., Jackson J., Carlson M., Mandel D., Hay J., Josephson K., Cherry B., Hessel C., Palmer J., Lipson L. (1997), Occupational therapy for independent-living older adults. A randomized controlled trial. JAMA 278, p. 1321-1326.

5. Clark F., Jackson J., Carlson M., Chou C-P., Cherry B., Jordan-Marsh M., Knight B., Mandel D., Blanchard J., Granger D., Wilcox R., Ying Lai M., White B., Hay J., Lam C., Marterella A., Azen S. (2011), Effectiveness of a lifestyle intervention in promoting the well-being of independently living older people: results of the Well Elderly 2 Randomized Controlled Trial. Journal of Epidemiology and Community Health Online First. 10.1136/ jech.2009.099754. http://jech.bmj.com/content/66/9/782.long (19.01.2014)

6. Europejskie Biuro Światowej Organizacji Zdrowia, http://www.euro.who.int/en/what-we-do/health-topics/ Life-stages/healthy-ageing (19.01.2014)

7. Fernandez-Ballesteros R. (2006), GeroPsychology. An applied field for the 21st century. European Psychologist 11, 4, p. 312-323.

8. Gill T., Feinstein A. (1994), A critical appraisal of the quality of quality-of-life measurements. JAMA 24, 272, 8, p. 619-626.

9. Gromulska L., Wysocki M., Goryński P. (2008), Lata przeżyte w zdrowiu (Health Life Years, HLY). Zalecany przez Unię Europejska, syntetyczny wskaźnik sytuacji zdrowotnej ludności. Przegląd Epidemiologiczny 62, p. 811-820.

10. Horowitz B., Wong S., Dechello K. (2010), Intergenerational service learning: to promote active aging, and occupational therapy gerontology practice. Gerontology \& Geriatrics Education 31, 1, p. 75-91.

11. Jackson J., Carlson M., Zemke R., Mandel D., Clark F. (1998), Occupation in Lifestyle Redesign: The USC Well Elderly Study occupational therapy program. American Journal of Occupational Therapy 52, p. 326-336.

12. Jaeschke R., Guyatt G., Cook D., Miller J. (1999), Określanie i mierzenie jakości życia zwiq̨zanej ze zdrowiem. Medycyna Praktyczna 4, p. 155-162.

13. Kostka T., Kostka J. (2011), Fizjoterapia w geriatrii. W: red. J. Olszewski: Fizjoterapia w wybranych dziedzinach medycyny. Kompendium. Wyd. Lek. PZWL, Warszawa, p. 329- 368.

14. Krampe J., Rantz M., Dowell L., Schamp R., Skubic M., Abbott C. (2010), Dance-based therapy in a program of all-inclusive care for the elderly: an integrative approach to decrease fall risk. Nursing Administration Quarterly 34, 2, p. 156-61.

15. Matuska K., Giles-Heinz A., Flinn N., Neighbor M., Bass-Haugen J. (2003), Outcomes of a pilot occupational therapy wellness program for older adults. American Journal of Occupational Therapy 57, 2, p. 220-224.

16. McCormac G. (1997), The role of occupational therapy in home care. Home Care Provider 2, p. 19-21.

17. Metz A., Robnett R. (2011), Engaging in mentally challenging occupations promotes cognitive health throughout life. Gerontology Special Interest Section Quarterly 34, 2, p. 1-4.

18. Nutbeam D. (1998), Health Promotion Glossary. World Health Organization, Geneva.

19. Perrin T. (2005), The role of occupational therapist. Psychiatry 4, 2, p. 93-94.

20. Quality of Life Assessment. The WHOQOL Group (1996), What Quality of Life? The WHOQOL Group. W: World Health Forum. WHO, Geneva.

21. Steultjens EM, Dekker J, Bouter LM, Jellema S, Bakker EB, van den Ende CH. (2004), Occupational therapy for community dwelling elderly people: a systematic review. Age Ageing, 33, 5, p. 453-460.

Source of thesis financing: The thesis was written as a part of the scholarship project "Development of the pedagogic- scientific potential within the scope of the occupational therapy as a key to Higher Education development" co-financed by the European Social Fund. 